\section{Kastamonu Eğitim Dergisi Kastamonu Education Journal}

Temmuz 2019 Cilt:27 Sayı:4

kefdergi.kastamonu.edu.tr
Başvuru Tarihi/Received: 31.05.2018

Kabul Tarihi/Accepted: 07.10.2018

DOI: 10.24106/kefdergi.3124

\title{
Öğretmen Adaylarının Teknoloji Entegrasyonuna Yönelik İnançları: Teknoloji Uyarlamaları Uygulama Ölçeğinin Türkçeye Uyarlanması
}

\section{Pre-service Teachers' Beliefs towards Technology Integration: Adaptation of Technology Implementation Questionnaire (TIQ) into Turkish}

\section{Öz}

\author{
Gülşah ULUAY ${ }^{1}$, Gözde ÇALIŞKANER NIBAT'2 ${ }^{2}$ Nihat ARIKAN ${ }^{3}$
}

Bu çalışmanın amacı Wozney, Venkatesh ve Abrami (2006) tarafindan geliştirilen "Teknoloji Uyarlamaları Uygulama Ölçeği"nin Türkçeye uyarlanmasıdır. Öncelikle, araştırmacılardan izin alınmış ve ardından çeviri yapılarak dil geçerliği süreci tamamlanmıştı. Araştırmanın çalışma grubunu eğitim fakültesinde öğrenim görmekte olan 423 üniversite öğrencisi oluşturmaktadır. Öncelikle, ölçeğin var olan teorik yapısını test etmek amacıyla doğrulayıcı faktör analizi (DFA) uygulanmıştır. DFA sonuçları, orijinal ölçek yapısının doğrulanmadığını göstermiştir. Bu nedenle, veri seti değerlendirilmiş ve açımlayıcı faktör analizi (AFA) uygulanmıştır. AFA ile toplam varyansın $\% 57,48$ 'ini açıklayan iki faktörlü ölçek yapısı elde edilmiştir. Bu yapı ikinci DFA ile sınanmış ve modelin mükemmel uyum gösterdiği sonucuna ulaşılmıştır. Madde analizi sürecinde madde toplam korelasyon değerleri ve \%27'lik alt-üst grup farkları belirlenmiştir. Ölçeğin güvenirliğinin belirlenmesinde iç tutarlık katsayısı incelenmiştir. Analiz sonuçları ışı̆̆ında, iki faktörlü yapıdaki 12 maddeden oluşan altılı Likert tipindeki ölçek elde edilmiştir. Bu bağlamda, ölçeğin Türkçe formunun geçerli ve güvenilir olduğu sonucuna ulaşılmıştr.

Anahtar Kelimeler: teknoloji entegrasyonu, inanç, ölçek uyarlama.

\section{Abstract}

The purpose of the study is to adapt the scale termed as "Technology Implementation Questionnaire (TIQ) Section I" been developed by Wozney, Venkatesh and Abrami (2006) into Turkish. Firstly, the permission was gotten from the researchers and process of language validity was completed by making translation. Participants of the study were 423 university students who were studying at education faculty. To test existing theoretical structure of the scale, confirmatory factor analysis (CFA) was implemented. Results of CFA showed that the structure wasn't confirmed. Then, data set was evaluated and exploratory factor analysis (EFA) was implemented. Two-factor model explained $57.48 \%$ of total variance was obtained. This structure was tested with second DFA and the model was confirmed with excellent fit indices. In process of item analysis, total item correlation coefficients and differences of $27 \%$ upper and $27 \%$ lower quantiles were determined. Internal consistency coefficient was evaluated to determine reliability of the scale. According to analysis results, 6-point Likert-type scale in two-factor structure that composes of 12 items was acquired. In this context, it was reached the conclusion that Turkish adaption of the scale was valid and reliable.

Keywords: technology integration, belief, adapting scale.

1. Kırşehir Ahi Evran Üniversitesi, Eğitim Fakültesi, Kırşehir, Türkiye, https://orcid.org/0000-0002-6365-5122

2. Kırşehir Ahi Evran Üniversitesi Yüksek Lisans Öğrencisi, Kırşehir, Türkiye, https://orcid.org/0000-0002-8055-0496

3. Kırşehir Ahi Evran Üniversitesi, Eğitim Fakültesi, Kırşehir, Türkiye, https://orcid.org/0000-0001-8028-313

Atıf / Citation: Uluay, G., Çalışkaner-Nibat, G., \& Arıkan, N. (2019). Öğretmen adaylarının teknoloji entegrasyonuna yönelik inançları: teknoloji uyarlamaları uygulama ölçeğinin Türkçeye uyarlanması. Kastamonu Education Journal, 27(4), 1529-1540. doi:10.24106/kefdergi.3124 


\section{Extended Abstract}

Integrating technology into teaching and learning environments has become a popular topic nowadays (Hew and Brush, 2007; Dolenc and Aberšek, 2015; Ashrafzadeh and Sayadian, 2015; Jonassen, 1992; Locatis, Letourneau and Banvard, 1989; Marsh and Kumar, 1992; Yoder, 1994). Despite the increasing use of technology in learning and teaching processes, the integration of technology into education is still seen as a complex process (e.g., Berrett Murphy and Sullivan,2012; Inan and Lowther, 2010). Existence of a wide variety of factors' effects on technology integration (e.g., Albion, 1999; Al-Awidi and Alghazo, 2012; Teo, 2011), can be seen among the reasons of this situation. One of the mentioned factors is explained as teachers' pedagogical beliefs (HSu, 2013; Kim, Kim, Lee, Spector and DeMeester, 2013; Liu, 2012; An and Reigeluth, 2012; Ertmer, Paul, Molly, Eva and Denise, 1999; Russell, Bebell, O'Dwyer and O'Connor, 2003; Wright and Wilson, 2011; Oliver and Shapiro, 1993). As a matter of fact, the study conducted by Russell, O'Dwyer, Bebell and Miranda (2004) stated that teachers should have positive technological beliefs in order to use technology in the classroom.

Belief is defined as subjective judgments about themselves and their surroundings (Fishbein and Ajzen, 1975). A teacher's pedagogical belief system involves a complex and multifaceted structure of beliefs about teaching and learning (Ertmer and Ottenbreit-Leftwich 2010; Hermans, Tondeur, van Braak and Valcke, 2008). In this context, it appears that teachers' beliefs are described as internal constructs that help them to interpret their own experiences and guide them to special teaching practices (Nespor, 1987; Pajares, 1992). From this point of view, the pedagogical beliefs of teachers are seen as a critical personal factor that affects their decision to use technology in teaching practice (HSu, 2013; Kim, Kim, Lee, Spector and DeMeester, 2013; Liu, 2012). In this context, it is thought that it is very important to determine the belief levels of teachers for technology integration. The purpose of the study is to adapt the scale termed as "Technology Implementation Questionnaire (TIQ) Section I" been developed by Wozney, Venkatesh and Abrami (2006) into Turkish.

Method: Participants of the study are composed of 423 university students who study at the faculty of education. There were 227 women (53.7\%) and 196 men (46.3\%) and the age range was between 19 and 26 . The average age of the study group is 20.55 .

Firstly, the permission was gotten from the researchers and process of language validity was completed by making translation. To test existing theoretical structure of the scale, confirmatory factor analysis (CFA) was implemented. Then, data set was evaluated and exploratory factor analysis (EFA) was implemented. In process of item analysis, total item correlation coefficients and differences of $27 \%$ upper and $27 \%$ lower quantiles were determined. Internal consistency coefficient was evaluated to determine reliability of the scale.

Findings: In the process of CFA, the model of the scale was investigated by means of fit indices that were termed as RMSEA (Root Mean Square Error of Approximation), CFI (Comparative Fit Indices), GFI (Goodness of Fit Index), AGFI (Adjusted Goodness of Fit Index), NNFI (Non-Normed Fit Index), SRMR (Standardized Root Mean Square Residual). For $\mathrm{CFI}, \mathrm{GFI}, \mathrm{NNFI}$, and AGFI fit indices, it is stated that .90 and values above show acceptable fit and for mentioned indices .95 and values above indicate perfect fit. Besides, it is indicated that the RMSEA and SRMR index values at .05 and below represent perfect fit (Jöreskog and Sörbom, 1993).

According to analysis results of CFA, it was found that the original structure of the scale wasn't confirmed. Thus, the process of evaluating the data set was started. At this stage, the process of item analysis was carried out. In this context, 13 items were excluded from the item pool because they had total correlations under .30 (5, 8, 9, 14, 15, 23, 24, 25, 27, 29, 30, 31 and 33). Thereafter EFA was applied to determine the validity of the scale. For determination of factors, variables with loads of .40 and higher are taken into account (Hair, Anderson, Tahtam and Black, 1998). According to EFA results, 8 items were removed from the scale $(1,7,12,17,18,19,21$ and 22). Two-factor model explained 57.48\% of total variance was obtained. This structure was tested with second DFA and the model was confirmed with excellent fit indices. According to analysis results, 6-point Likert-type scale in two-factor structure that composes of 12 items was acquired. Following the completion of the second DFA process, the item analysis process was applied. At this stage, the Spearman-Brown method was used to evaluate the consistency of the scale items. When the obtained analysis results are examined, it is seen that the correlation coefficient between the items is sufficient.

Internal reliability of the scale was evaluated with Cronbach's Alpha coefficient value. At this stage, Cronbach's Alpha coefficient values of the scale and each factor was founded. According to analysis results, it was seemed that the scale was reliable.

Conclusion : According to the results of the validity and reliability analysis of TIQ, it was reached the conclusion that Turkish adaption of the scale was valid and reliable. The scale can be used to determine pre-service teachers' beliefs towards technology integration into classrooms. The scale consisted of 6-point Likert type scale ( $1=$ Strongly Disagree, 2 = Moderately Disagree, 3 = Slightly Disagree, 4 = Slightly Agree, 5 = Moderately Agree, and 6 = Strongly Agree) .

When support that was presented to learning processes of students by means of technology use in classrooms (e.g., Cradler, McNabb, Freeman and Burchett, 2002; Roschelle, Abrahamson and Penuel, 2004; Bajcsy, 2002; Watson, 2007) and beliefs' effect on teachers' actions were taken into consideration (Russell, 0’Dwyer, Bebell and Miranda, 2004; Honey and Moeller, 1990; Cuban, 2002; Fullan, 2001; Fullan, 2003; Guskey, 2002; Ringstaff and Kelley, 2002; Sandholtz, Ringstaff, and Dwyer, 1997), the importance of teachers' beliefs towards technology use in educational environments emerge. For example, in the study that was conducted by Coppola (2004), it is stated that teachers only use technology when they really believe in its value. In this context, it can be said that it is very important to determine the level of teacher beliefs about instructional technologies. Consequently, TIQ that was adapted into Turkish with this study can be used for this purpose. 


\section{Giriş}

Teknolojinin öğretim ve öğrenim ortamlarına entegre edilmesi günümüzde oldukça popüler bir konu olmuştur (Hew \& Brush, 2007; Dolenc \& Aberšek, 2015; Ashrafzadeh \& Sayadian, 2015; Jonassen, 1992; Locatis, Letourneau, \& Banvard, 1989; Marsh \& Kumar, 1992; Yoder, 1994). Bu durumun en önemli nedenlerinden biri, öğretim teknolojilerinin eğitsel süreçlere sunmuş olduğu katkılar olarak ifade edilebilir. Nitekim en verimli eğitsel teknoloji uygulamaları öğrenci merkezli öğrenmeyi teşvik eden uygulamalar olarak tanımlanmaktadır (Becker, 1994; Bigatel, 2004; Coppola, 2004; Moersch, 2002). Öğrenci merkezli eğitsel ortamlar öğrenmeyi kişiselleştirmekte, öğrencilere duygusal ve sosyal destek sağlamakta, öğrencilere kendi öğrenmelerini nasıl düzenleyeceklerini öğretmekte, işbirliği ve otantik öğrenme için firsatlar sağlamakta ve öğrenmeye yönelik değerlendirmeleri içermektedir (An \& Reigeluth, 2012). Buradan hareketle, teknolojinin "anlamlı öğrenme için gerekli yüksek öğrenme ve üst bilişsel becerileri" teşvik ederek öğrenciye yardımcı olabildiği (Wang, Kinzie, McGuire, \& Pan, 2010, s. 382) belirtilmektedir. Bunun yanı sıra, teknoloji donanımlı sınıfların eleştirel düşünürler ve liderler yetiştirme imkânı sunduğu ifade edilmektedir (Bingimlas, 2009; McMahon, 2009).

Öğrenme ve öğretme süreçlerinde teknoloji kullanımının giderek artmasına rağmen teknolojinin eğitime entegrasyonu hala karmaşık bir süreç olarak görülmektedir (Berrett Murphy \& Sullivan,2012; Inan \& Lowther, 2010). Teknoloji entegrasyonu üzerinde çok çeşitli faktörlerin etkili olması (Albion, 1999; Al-Awidi \& Alghazo, 2012; Teo, 2011), bu durumun nedenleri arasında görülebilir. Söz konusu faktörlerden biri de öğretmenlerin pedagojik inançları olarak açıklanmaktadır (HSu, 2013; Kim, Kim, Lee, Spector, \& DeMeester, 2013; Liu, 2012; An \& Reigeluth, 2012; Ertmer, Paul, Molly, Eva, \& Denise, 1999; Russell, Bebell, O’Dwyer, \& O'Connor, 2003; Wright \& Wilson, 2011; Oliver \& Shapiro, 1993). Nitekim Russell, O'Dwyer, Bebell, ve Miranda (2004) tarafından yürütülen çalışmada, sınıflarda teknoloji kullanımını sağlamak için öğretmenlerin teknolojiye yönelik olumlu inançlara sahip olması gerektiği belirtilmiştir. Bununla birlikte Honey ve Moeller (1990), yapılandırmacı pedagojik inançlara sahip olan öğretmenlerin teknolojiyi öğretim süreçlerine başarıyla entegre ettiğini ifade etmektedir.

Illgili literatür incelendiğinde, inanç ve öğretmen inançları kavramlarına yönelik çok çeşitli tanımların söz konusu olduğu görülmektedir (Pajares, 1992; Ertmer 2005; Hermans, Tondeur, van Braak, \& Valcke, 2008). Örneğin; Pajares (1992, s. 307), inanç kavramını "dağınık bir yapı" olarak tanımlamakta ve inançların "bireylerin hayatları boyunca aldıkları kararların en iyi göstergeleri" olduğunu ifade etmektedir. Bunun yanı sıra inanç, insanların kendileri ve çevreleri hakkındaki öznel yargıları olarak da tanımlanmaktadır (Fishbein \& Ajzen, 1975). İnançların eğitim ve öğretim süreçlerinde de etkili olduğu görülmektedir. Nitekim bir öğretmenin pedagojik inanç sistemi, öğretme ve öğrenmeye ilişkin inançların karmaşık ve çok yönlü bir yapısını içermektedir (Ertmer \& Ottenbreit-Leftwich 2010; Hermans, Tondeur, van Braak, \& Valcke, 2008). Bu bağlamda, öğretmenlerin sahip olduğu inançların kendi deneyimlerini yorumlamalarına ve özel öğretim uygulamalarına rehberlik etmelerine yardımcı olan içsel yapılar olarak açıklandığı görülmektedir (Nespor, 1987; Pajares, 1992).

Öğretmenlerin inançları, kararlarını ve sınıfta yürüttükleri eylemlerini yönlendirmektedir (Cuban, 2001; Fullan, 2001; Fullan, 2003; Guskey, 2002; Ringstaff \& Kelley, 2002; Sandholtz, Ringstaff, \& Dwyer, 1997). Öğretmen inançlarının geçmişten gelen öğretim ve / veya öğrenme deneyimlerine derinden bağlı olabileceği düşünülmektedir (Holland, Lachicotte, Skinner, \& Cain, 1998; Thomas, 2003). Yani öğretmen adaylarının, öğrenenler olarak kendi deneyimleri aracılığıyla geliştirdikleri bir dizi inançla eğitim programlarına geldikleri ve sahip oldukları bu deneyimlerinin gelecekteki uygulamalarını şekillendirmelerinde önemli bir rol oynadığı kabul edilmektedir (Kennedy, 1997; Richardson, 2003). Bu bağlamda, öğretim teknolojilerinin sınıf ortamında kullanılması noktasında öğretmen inançlarının önemli olduğu ifade edilebilir. Nitekim öğretmenlerin pedagojik inançları, öğretim uygulamalarında teknolojiyi kullanma kararlarını etkileyen kritik bir kişisel faktör olarak görülmüştür (HSu, 2013; Kim, Kim, Lee, Spector, \& DeMeester, 2013; Liu, 2012). Yani, öğretim süreçlerine teknoloji entegrasyonunun sağlanması için öğretim teknolojilerini kullanma becerilerine ihtiyaç duyulmasının yanı sıra bu teknolojilerin öğretim ve öğrenime nasıl katkı sağlayabildiğine ilişkin inançlara da gereksinim duyulmaktadır (Ertmer, Ottenbreit-Leftwich, Sadik, Sendurur, \& Sendurur, 2012).

Sugar (2002), teknoloji entegrasyonunu sağlamak için öğretmenlerin teknoloji entegrasyonu ile ilgili inançlarını ele alma ve ikinci dereceden engelleri aşmanın önemini vurgulamıştır. Bu bağlamda, teknolojinin eğitimdeki önemi ve inançların öğretmen seçimleri üzerindeki etkileri göz önüne alındığında, öğretmen adaylarının teknoloji entegrasyonuna yönelik inanç düzeylerinin tespit edilmesinin oldukça önemli olduğu düşünülmektedir. Buradan hareketle, bu çalışmanın amacı Wozney, Venkatesh, ve Abrami (2006) tarafindan geliştirilen "Teknoloji Uyarlamaları Uygulama Ölçeği Bölüm 1" adlı ölçeğin Türkçe'ye uyarlanması olarak belirlenmiştir. Bu araştırmada, yeni bir ölçeğin geliştirilmesi yerine var olan bir ölçeğin uyarlanmasının tercih edilme nedeni ise öğretmen inanç sistemlerinin etkileşimli, kesişen ve birbiriyle örtüşen birçok inancı içermesi (Pajares, 1992) olarak ifade edilebilir. 


\section{Yöntem}

\section{Çalışma Grubu}

Araştırmanın çalışma grubunu eğitim fakültesinde öğrenim görmekte olan 423 üniversite öğrencisi oluşturmaktadır. Katılımcıların yaş aralığı 19 ve 26 aralığındadır ve yaş ortalaması 20,55'tir. Çalışma grubunun cinsiyet ve sınıf düzeyine ilişkin dağılımı Tablo 1'de sunulmaktadır.

\section{Tablo 1. Çalışma Grubu}

\begin{tabular}{llcc}
\hline \multirow{2}{*}{ Cinsiyet } & & $\mathrm{f}$ & $\%$ \\
& Kadın & 227 & $\% 53,7$ \\
& Erkek & 196 & $\% 46,3$ \\
\hline \multirow{2}{*}{ Sınıf } & 3. Sınıf & 237 & $\% 56$ \\
& 4. Sınıf & 186 & $\% 44$ \\
\hline
\end{tabular}

\section{Teknoloji Uyarlamaları Uygulama Ölçeği Bölüm 1}

Teknoloji Uyarlamaları Uygulama Ölçeği Bölüm 1, Wozney, Venkatesh, ve Abrami (2006) tarafindan geliştirilmiştir. Bu ölçeğin amacı, öğretmen adaylarının öğretim ortamlarında teknoloji kullanımına yönelik inançlarını tespit etmektir. Uyarlama çalışması yapılmış olan $6^{\prime}$ Iı Likert tipindeki $(1=$ Kesinlikle Katılmıyorum, $\ldots, 6=$ Kesinlikle Katlıyorum $)$ bu ölçek, 3 alt boyuttan oluşmaktadır. Bu boyutlar; (1) beklenti, (2) değer ve (3) maliyet olarak belirtilmektedir. Ölçeğin orijinal versiyonunda "beklenti" faktörü altında 10 madde (örneğin, "Sınıflarda bilgisayar teknolojisi kullanımı, ancak teknik ekip düzenli olarak bilgisayarların bakımını yaparsa başarılı olur."), "değer" faktörü altında 14 madde (örneğin, "Sınıflarda bilgisayar teknolojisi kullanımı, iletişim becerilerinin (ör: yazma ve sunum becerileri) gelişimini destekler.") ve "maliyet" faktörü altında 9 madde (örneğin, "Sınıflarda bilgisayar teknolojisi kullanımı kaynaklar, zaman ve çaba açısından çok pahalıdır.") bulunmaktadır.

Ölçeğin çeviri sürecinde çeviri-geri çeviri yöntemi (Brislin, 1970) kullanılmıştr. Bu yönteme göre, kültürler arası yürütülen bir araştırma için araştırmacı şu kuralları takip etmelidir: (1) basit cümleler, (2) zamir kullanımı yerine isimlerin tekrar edilmesi, (3) metafor ve gündelik anlatımdan kaçınma, (4) İngilizce edilgen çatıdan kaçınma ve (5) varsayımsal ifadelerden ya da istek kiplerinden kaçınma (Campbell, Brislin, Stewart, \& Werner, 1970). Brislin'e (1970) göre, bu kurallar çerçevesinde her iki dili bilen araştırmacılar ile çeviri çalışması yapılır. Bu noktada, ilk olarak kaynak dilden hedef dile çeviri yapııır. Ardından, farklı bir araştırmacı kaynak dildeki orijinal metni görmeksizin hedef dile çevrilen formu tekrar kaynak diline çevirir. Elde edilen iki form arasındaki denklik incelenir ve çeviri süreci tamamlanır. Bu araştırmada, beş araştırmacı birbirinden bağımsız olarak orijinal ölçek formunu Türkçeye çevirmiştir. Ardından, Türkçe formdaki ölçek maddeleri farkıı iki araştırmacı tarafindan tekrar İngilizceye çevrilmiştir. Çevirilerin tamamlanmasının ardından düzenlenen bir oturum kapsamında, çeviriyi yapan araştırmacılar ve iki alan uzmanı ile maddeler değerlendirilmiştir. Görüş birliğine varılmasının ardından, ölçeğin Türkçe formu hazırlanmıştır.

Bu çalışma kapsamında elde edilen veriler ilk olarak doğrulayıcı faktör analizine (DFA) tabi tutulmuştur. İlk aşamada DFA kullanıımasının amacı, araştırma kapsamında elde edilen veri seti ile ölçeğin orijinal versiyonunu karşılaştırmaktır. Bu aşamanın ardından verilerin değerlendirilmesi sürecine geçilmiştir. Uç değerleri tespit etmek amacıyla toplam ölçek puanları Z puanına dönüştürülmüştür. Bu noktada, -3 ve +3 aralığının dışında kalan Z puanına sahip katılımcı sonuçları analiz sürecinden çıkarılmıştır $(n=6)$. Ardından, ölçek maddelerinin homojen bir yapı gösteren bir bütünü temsil edip etmediğini tespit etmek için ölçeğe ilişkin Cronbach Alpha katsayısı hesaplanmıştr. Her bir maddenin ölçeğin tamamıyla olan ilişkisini tespit etmek amacıyla korelasyon katsayısı incelenmiş ve ,30'un altında madde toplam korelasyonuna sahip ölçek maddeleri formdan çıkarılmıştı. Ardından, ölçek bünyesindeki faktörleri incelemek için AFA uygulanmış ve elde edilen model ikinci DFA ile sınanmıştr.

\section{Bulgular}

Çalışmanın bu bölümünde uyarlama sürecinde izlenen analiz basamakları ve elde edilen bulgular sırasıyla sunulmaktadır. Bu bağlamda, izlenen basamaklar sırasıyla şu şekildedir: (1) DFA sonuçları, (2) veri setinin değerlendirilmesi, (3) AFA sonuçları, (4) ikinci DFA sonuçları, (5) madde analizi ve (6) iç güvenilirlik sonuçları.

\section{Doğrulayıcı Faktör Analizi}

DFA var olan teorik modeli ve faktör yapısını sınamak için kullanılmıştır (Thompson, 2004). Bu çalışmada, Wozney, 
Venkatesh, ve Abrami (2006) tarafindan belirlenen ölçek faktör yapısının doğrulanması için ilk olarak DFA uygulanmıştr. DFA ile değerlendirilen model, RMSEA (Root Mean Square Error of Approximation), CFI (Comparative Fit Indices), GFI (Goodness of Fit Index), AGFI (Adjusted Goodness of Fit Index), NNFI (Non-Normed Fit Index), SRMR (Standardized Root Mean Square Residual) uyum indeksleri doğrultusunda incelenmiştir. CFI, GFI, NNFI ve AGFI uyum indeksleri için .90 ve üzeri değerlerin kabul edilebilir uyumu; söz konusu indekslerin .95 ve üzeri değerlerinin ise mükemmel uyumu gösterdiği ifade edilmektedir. Bunun yanı sıra, .05 ve altındaki RMSEA ve SRMR indeks değerlerinin mükemmel uyumu temsil ettiği belirtilmektedir (Jöreskog and Sörbom, 1993).

DFA aracılığıyla elde edilen sonuçlara göre Chi-Square $=2045.86(\mathrm{~N}=423, \mathrm{Sd}=492), \mathrm{p}<.001, \mathrm{CFI}=.57 ; \mathrm{GFI}=.77$, $\mathrm{AGFI}=.74, \mathrm{NNFI}=.54, \mathrm{RMSEA}=.087(\% 90 \mathrm{Cl}=.083 ; .090)$, SRMR $=.012$ olarak bulunmuştur. Bu aşamada, elde edilen DFA sonuçları doğrultusunda var olan faktör yapısının doğrulanmadığı görülmüştür. Buradan hareketle veri setinin değerlendirilmesi sürecine geçilmiştir.

\section{Verilerin Değerlendirilmesi}

Bu aşamada madde analizi süreci yürütülmüştür. Öncelikle, 429 üniversite öğrencisinden elde edilen ölçek verileri Z puanı ile incelenmiştir. Ardından, elde edilen veri setinin homojen bir bütün olup olmadığını tespit etmek adına Cronbach Alpha analizi uygulanmıştır. Ayrıca, her bir maddenin ölçeğin tamamına etkisi incelenmiştir. Bu bağlamda, 12 madde .30 'un altında madde toplam korelasyonuna sahip olduğu için ölçeğe ait madde havuzundan çıkarılmıştı $(8,9$, $14,15,23,24,25,27,29,30,31$ ve 33). Analiz sonuçları Tablo 2'de gösterilmektedir.

\section{Tablo 2. Ölçek Maddelerine Ait Cronbach's Alpha Değerleri}

\begin{tabular}{|c|c|c|c|c|}
\hline Madde & $\begin{array}{l}\text { Madde Silinirse } \\
\text { Ortalama }\end{array}$ & $\begin{array}{c}\text { Madde Silinirse } \\
\text { Varyans }\end{array}$ & $\begin{array}{c}\text { Düzeltilmiş Madde Toplam } \\
\text { Korelasyonu }\end{array}$ & $\begin{array}{l}\text { Madde Silinirse } \\
\text { Cronbach's Alpha }\end{array}$ \\
\hline 1 & 95,04 & 495,17 &, $721^{* *}$ & ,85 \\
\hline 2 & 94,17 & 503,58 &, $583^{* *}$ & ,85 \\
\hline 3 & 94,58 & 499,70 &, $644^{* *}$ & ,85 \\
\hline 4 & 94,91 & 500,43 &, $665^{* *}$ & ,85 \\
\hline 5 & 93,67 & 523,70 &, $338^{* *}$ & ,86 \\
\hline 6 & 94,86 & 512,26 &, $501^{* *}$ & ,86 \\
\hline 7 & 95,00 & 498,00 &, $719^{* *}$ & ,85 \\
\hline 8 & 93,33 & 545,92 & ,035 & 87 \\
\hline 9 & 94,01 & 552,22 &,- 051 & 87 \\
\hline 10 & 95,15 & 507,26 &, $588^{* *}$ & ,85 \\
\hline 11 & 94,60 & 500,98 &, $626^{* *}$ & ,85 \\
\hline 12 & 94,36 & 506,92 &, $531^{* *}$ & ,85 \\
\hline 13 & 94,94 & 501,22 & ,618 & ,85 \\
\hline 14 & 93,25 & 546,45 & ,030 & ,87 \\
\hline 15 & 93,77 & 543,06 & 079 & ,86 \\
\hline 16 & 94,72 & 522,32 &, $381^{* *}$ & ,86 \\
\hline 17 & 94,60 & 517,88 &, $449^{* *}$ & ,86 \\
\hline 18 & 94,91 & 499,15 & ,692 & ,85 \\
\hline 19 & 94,17 & 503,58 &, $583^{* *}$ & ,85 \\
\hline 20 & 94,36 & 509,60 &, $500^{* *}$ & ,86 \\
\hline 21 & 94,98 & 497,70 & ,720** & ,85 \\
\hline 22 & 95,00 & 495,23 & ,739** & ,85 \\
\hline 23 & 93,55 & 534,74 & 170 & ,86 \\
\hline 24 & 93,48 & 541,00 & ,096** & ,86 \\
\hline 25 & 93,18 & 551,18 &,- 037 & 87 \\
\hline 26 & 95,01 & 508,39 &, $623^{* *}$ & ,85 \\
\hline 27 & 93,77 & 531,59 & 238 & ,86 \\
\hline 28 & 94,35 & 506,18 &, $561^{* *}$ & ,85 \\
\hline 29 & 93,31 & 551,89 &,- 048 & 87 \\
\hline 30 & 93,87 & 541,18 & ,054 & ,87 \\
\hline 31 & 93,04 & 558,76 &,- 137 & ,87 \\
\hline 32 & 95,02 & 506,15 & ,659** & ,85 \\
\hline 33 & 93,81 & 555,55 &,- 093 & ,87 \\
\hline
\end{tabular}


Tespit edilen maddelerin çıkarılmasının ardından aynı analiz süreci veri setini kontrol etmek için tekrar uygulanmıştr. Bu aşamada, 5 numaralı maddeye ilişkin korelasyon değeri .30'un altında olduğu için söz konusu madde ölçek bünyesinden çıkarılmıştır. Analiz sonuçları Tablo 3'te sunulmaktadır.

Tablo 3. Ölçek Maddelerine Ait Cronbach's Alpha Değerleri

\begin{tabular}{ccccc}
\hline Madde & $\begin{array}{c}\text { Madde Silinirse } \\
\text { Ortalama }\end{array}$ & $\begin{array}{c}\text { Madde Silinirse } \\
\text { Varyans }\end{array}$ & $\begin{array}{c}\text { Düzeltilmiş Madde Toplam } \\
\text { Korelasyonu }\end{array}$ & $\begin{array}{c}\text { Madde Silinirse } \\
\text { Cronbach's Alpha }\end{array}$ \\
\hline 1 & 50,87 & 453,97 &, $776^{* *}$ &, 93 \\
2 & 50,00 & 467,24 &, $561^{* *}$ &, 93 \\
3 & 50,41 & 460,16 &, $731^{* *}$ &, 93 \\
4 & 50,74 & 458,11 &, $245^{* *}$ &, 94 \\
5 & 49,50 & 491,81 &, $549^{* *}$ &, 93 \\
6 & 50,69 & 470,87 &, $769^{* *}$ &, 93 \\
7 & 50,82 & 457,18 &, $664^{* *}$ &, 93 \\
10 & 50,98 & 464,42 &, $656^{* *}$ &, 93 \\
11 & 50,43 & 461,16 &, $578^{* *}$ &, 93 \\
12 & 50,19 & 465,62 &, $646^{* *}$ &, 93 \\
13 & 50,77 & 461,52 &, $458^{* *}$ &, 93 \\
16 & 50,55 & 478,77 &, $466^{* *}$ &, 93 \\
17 & 50,43 & 478,43 &, $750^{* *}$ &, 93 \\
18 & 50,74 & 457,67 &, $561^{* *}$ &, 93 \\
19 & 50,00 & 467,24 &, $501^{* *}$ &, 93 \\
20 & 50,19 & 471,46 &, $790^{* *}$ &, $811^{* *}$ \\
21 & 50,81 & 455,59 &, $696^{* *}$ &, $585^{* *}$ \\
22 & 50,82 & 453,00 &, $714^{* *}$ &, 93 \\
26 & 50,84 & 466,04 & &, 93 \\
28 & 50,18 & 466,59 & 93 \\
32 & 50,85 & 464,97 & &, 93 \\
\hline
\end{tabular}

$* * p<0.01$.

5 numaralı maddenin ölçekten çıkarılmasının ardından veri seti tekrar kontrol edilmiş ve her bir maddenin ,30'un üzerinde madde toplam korelasyonuna sahip olduğu görülmüştür. Ardından, açımlayıcı faktör analizi sürecine geçilmiştir.

\section{Açımlayıcı Faktör Analizi}

Teknoloji Uyarlamaları Uygulama Ölçeği Bölüm 1'in geçerliğini tespit etmek amacıyla açımlayıcı faktör analizi (AFA) uygulanmıştr. AFA sonuçlarına göre faktörlerin belirlenmesi aşamasında, .40 ve daha yüksek değerdeki yüklere sahip değişkenler dikkate alınmıştı (Hair, Anderson, Tahtam and Black, 1998). Ayrıca, farklı faktörlerde .10'dan düşük faktör yükü farkına sahip maddeler binişik olduğu için madde havuzundan çıkarılmıştır (Yavuz, 2005). Bu bağlamda, 6 madde binişik özellik gösterdiği için ölçek dışında bırakılmıştı $(1,7,12,18,21$ ve 22). Bununla birlikte, nomolojik geçerlilik kapsamında maddeler teorik yapı ışı̆̆ında değerlendirilmiştir. Bu noktada, araştırmacılar ölçek ile tutarlılık göstermeyen maddeleri havuzdan çıkarabilmektedir (Şencan, 2005). Buradan hareketle 2 madde kuramsal yapıya uygun olmadığı için madde havuzundan çıkarılmıştır (17 ve 19).

Maddelerin elenmesi sürecinin ardından AFA tekrar uygulanmıştır. Bu noktada, KMO değeri .92 olarak hesaplanmış ve Barletts Testi sonuçları istatistiksel olarak anlamlı bulunmuştur $\left(\mathrm{Chi}^{2}{ }_{(66)}=2142.26, \mathrm{p}<.001\right)$. Bu sonuçlar doğrultusun$\mathrm{da}$, verilerin AFA için uygun olduğu ve katılımcı sayısının yeterli olduğu sonucuna ulaşılmıştır. Elde edilen AFA sonuçları doğrultusunda, toplam varyansın \%57,48'ini açıklayan iki faktörlü ölçek yapısı elde edilmiştir. Faktör yük değerlerinin ,59 ve ,80 arasında değişkenlik gösterdiği sonucuna ulaşıımıştır. AFA sonuçları Tablo 4'te sunulmaktadır. 
Tablo 4. AFA Sonuçları

\begin{tabular}{|c|c|c|c|c|c|c|}
\hline \multirow{2}{*}{ Maddeler } & \multicolumn{3}{|c|}{ Birinci AFA } & \multirow{2}{*}{ Maddeler } & \multicolumn{2}{|c|}{ İkinci AFA } \\
\hline & Faktör 1 & Faktör 2 & Faktör 3 & & Faktör 1 & Faktör 2 \\
\hline 20 & 76 & & & 10 & ,80 & \\
\hline 3 & 74 & & & 16 & 75 & \\
\hline 28 & 72 & & & 26 & 73 & \\
\hline 11 & ,64 & & & 4 & ,67 & \\
\hline 13 & 61 & & & 6 & 66 & \\
\hline 21 & 61 & & & 32 & 63 & \\
\hline 18 & ,59 & & & $2^{*}$ & ,43 & \\
\hline 17 & ,43 & & & 20 & & 79 \\
\hline 10 & & ,78 & & 3 & & ,76 \\
\hline 16 & & 76 & & 28 & & 73 \\
\hline 26 & & 68 & & 11 & & 63 \\
\hline 6 & & ,65 & & 13 & & ,63 \\
\hline 4 & & 63 & & & & \\
\hline 32 & & ,59 & & & & \\
\hline 22 & & ,56 & & & & \\
\hline 7 & & ,54 & & & & \\
\hline 1 & & ,53 & & & & \\
\hline 12 & & ,44 & & & & \\
\hline 2 & & & ,95 & & & \\
\hline 19 & & & ,95 & & & \\
\hline Açıklanan Varyans & 25,37 & 49,84 & 62,35 & & 30,61 & 57,48 \\
\hline Özdeğer & 9,68 & 1,48 & 1,29 & & 5,59 & 1,30 \\
\hline
\end{tabular}

\section{íkinci Doğrulayıcı Faktör Analizi}

Elde edilen faktör yapısının doğruluğunun sınanması için ikinci DFA süreci 12 madde kapsamında uygulanmıştr. DFA aracılığıyla elde edilen sonuçlara göre Chi-Square $=142,33(\mathrm{~N}=423, \mathrm{Sd}=53), \mathrm{p}<, 001, \mathrm{CFI}=, 96 ; \mathrm{GFI}=, 95, \mathrm{AGFI}=, 92$, $\mathrm{NNFI}=, 95, \mathrm{RMSEA}=, 063(\% 90 \mathrm{Cl}=, 051 ;, 076), \mathrm{SRMR}=, 045$ şeklinde tespit edilmiştir. Bu bağlamda, belirtilen uyum indeksleri doğrultusunda modelin elde edilen yapı ile mükemmel düzeyde uyum gösterdiği sonucuna ulaşılmıştr. DFA sonuçları Şekil 1'de sunulmaktadır.

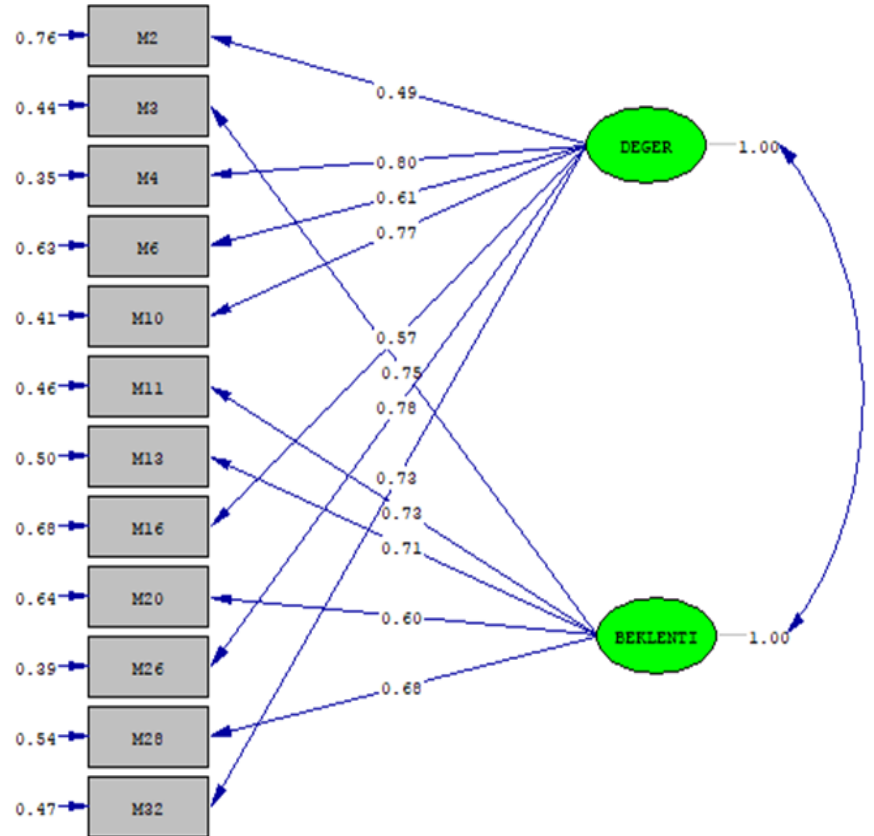

Chi-Square $=142.33, \mathrm{df}=53, \mathrm{p}-\mathrm{value}=0.00000, \mathrm{RMSEA}=0.063$

Şekil 1. Ölçek faktör yükleri 


\section{Madde Analizi}

îkinci DFA sürecinin tamamlanmasının ardından madde analizi süreci uygulanmıştır. Bu aşamada, ölçme aracını oluşturan maddelerin tutarılıklarını değerlendirmek adına Spearman-Brown metodu kullanılmıştır. Her bir ölçeğin toplam puanı belirlenmiş ve puanlar en düşükten en yükseğe doğru sıralanmıştır. Ardından, \%27'lik dilim kapsamında alt grup $\left(n_{1}=114\right)$ ve üst grup $\left(n_{2}=114\right)$ oluşturulmuştur. Elde edilen $r$ değerlerinin incelenmesi aşamasında ,30 değeri kesme noktası olarak kabul edilmiştir (Field, 2013; Nunnally \& Bernstein, 1994). Elde edilen analiz sonuçları incelendiğinde, maddeler arasındaki korelasyon katsayısının yeterli olduğu görülmüştür. Bu bağlamda, ölçekten herhangi bir madde çıkarılmamıştır. Ölçek maddelerine ilişkin madde toplam korelasyon katsayılarının ,67 ile ,85 arasında değişkenlik gösterdiği belirlenmiştir. Analiz sonuçları Tablo 5'te sunulmaktadır.

Tablo 5. Madde-Toplam Puan Korelasyonları ve Alt-Üst Grup Ortalamaları Arasındaki Farklar

\begin{tabular}{lccccc}
\hline Maddeler & $\overline{\mathrm{X}}$ & $\mathrm{SS}$ & $\mathrm{t}$-test & $\mathrm{p}$ & $\mathrm{r}$ \\
\hline 2 & 3,15 & 1,84 & 11,32 &, $000^{*}$ &, $67^{* *}$ \\
3 & 2,86 & 1,88 & 18,74 &, $000^{*}$ &, $83^{* *}$ \\
4 & 2,65 & 1,89 & 14,46 &, $000^{*}$ &, $85^{* *}$ \\
6 & 2,57 & 1,77 & 12,97 &, $000^{*}$ &, $73^{* *}$ \\
10 & 2,35 & 1,84 & 11,24 &, $000^{*}$ &, $81^{* *}$ \\
11 & 2,82 & 1,89 & 20,30 &, $000^{*}$ &, $84^{* *}$ \\
13 & 2,56 & 1,93 & 14,88 &, $000^{*}$ &, $80^{* *}$ \\
16 & 2,66 & 1,66 & 9,48 &, $000^{*}$ &, $68^{* *}$ \\
20 & 2,74 & 1,83 & 15,34 &, $000^{*}$ &, $73^{* *}$ \\
26 & 2,42 & 1,69 & 12,43 &, $000^{*}$ &, $79^{* *}$ \\
28 & 2,96 & 1,84 & 18,33 &, $000^{*}$ &, $82^{* *}$ \\
32 & 2,40 & 1,73 & 12,75 &, $000^{*}$ &
\end{tabular}

\section{İç Güvenilirlik}

İç güvenilirlik Cronbach's Alpha katsayısı ve maddelerin iki eşdeğer yarıya bölünmesi ile elde edilen güvenilirlik analizi (split-half reliability) ile değerlendirilmiştir. Teknoloji Uyarlamaları Uygulama Ölçeği Bölüm 1'e ilişkin Cronbach's Alpha katsayısının ,89 olarak bulunduğu görülmüştür. Bunun yanı sıra, değer faktörünün Cronbach's Alpha katsayısı ,85 ve beklenti faktörünün Cronbach's Alpha katsayısı ,82 olarak hesaplanmıştrr. Bu bağlamda, ölçeğin oldukça güvenilir olduğu sonucuna ulaşımıştır. Analiz sonuçları Tablo 6'da sunulmaktadır.

Tablo 6. İ̧ Tutarlılık, Ortalamalar ve Standart Sapmalar

\begin{tabular}{|c|c|c|c|c|c|c|c|c|}
\hline \multirow{2}{*}{ Ölçek } & \multicolumn{3}{|c|}{ Ranj } & \multirow{2}{*}{$\bar{x}$} & \multirow{2}{*}{ SS } & \multicolumn{3}{|c|}{ Korelasyon } \\
\hline & $\alpha$ & Min. & Max. & & & 1 & 2 & 3 \\
\hline 1. Ölçek & 89 & 12 & 71 & 29,86 & 7,93 & 1 & & \\
\hline 2. Değer & ,85 & 7 & 42 & 16,64 & 6,45 & ,92 & 1 & \\
\hline 3. Beklenti & ,82 & 5 & 30 & 13,22 & 13,05 & ,88 & ,64 & 1 \\
\hline
\end{tabular}

Analiz süreçlerinin tamamlanmasının ardından toplam varyansın \%57,48'ini açıklayan iki faktörlü ölçek yapısı elde edilmiştir. Bu noktada, değer kategorisi altında 7 madde $(2,4,6,10,16,26$ ve 32) ve beklenti kategorisi kapsamında 5 madde $(3,11,13,20$ ve 28$)$ olmak üzere 12 maddelik nihai ölçek elde edilmiştir.

\section{Sonuçlar ve Tartışma}

Bu çalışmanın amacı, Wozney, Venkatesh, ve Abrami (2006) tarafindan geliştirilen "Teknoloji Uyarlamaları Uygulama Ölçeği Bölüm 1" adlı ölçeğin Türkçe'ye uyarlanmasıdır. Bu amaç doğrultusunda, söz konusu ölçeğin geçerlik ve güvenirlik analizleri yapılmıştır. Araştırmacılardan izin alınmasının ardından çeviri işlemleri başlatılmış ve bu noktada çeviri-geri çeviri yöntemi kullanılmıştır. Süreç kapsamında, ölçeğin orijinal versiyonu beş farklı araştırmacı tarafindan Türkçe'ye çevrilmiş ve ardından tekrar İngilizce'ye çevrilerek maddelere ilişkin uzman görüşleri alınmıştır. Çeviri sürecinin tamamlanmasının ardından ölçeğin belirlenen faktör yapısı uyarlama çalışması kapsamında toplanan veriler ışı̆̆ında doğrulayıcı faktör analizi (DFA) ile sınanmıştr. Elde edilen DFA sonuçları, uyarlanan ölçek yapısının orijinal versiyonunu doğrulamadığını göstermiştir. Buradan hareketle, tüm maddelerin Cronbach's Alpha değerlerinin ve her bir maddenin ölçeğin 
tamamı üzerindeki etkisinin belirlenmesi ile veri seti değerlendirilmiştir. Ardından, açımlayıcı faktör analizi (AFA) süreci uygulanmış ve uyarlanan ölçeğin yapı geçerliliği kontrol edilmiştir. AFA ile elde edilen yapı, ikinci DFA ile sınanmıştr. Faktör analizlerinin tamamlanması ile madde analizi ve güvenirlik analizleri uygulanmıştır.

Veri setinin tekrar değerlendirilmesi sürecinde, 13 madde ,30'un altında madde toplam korelasyonuna sahip olduğu için madde havuzundan çıkarılmıştır. Ardından, ölçeğin faktör yapısını tespit etmek için AFA uygulanmıştır. Analiz sürecinde, faktör yüklerinin belirlenmesi aşaması için kesme noktası, 40 olarak belirlenmiştir. Ayrıca, her bir maddenin farklı faktörlerdeki yük değerleri incelenmiş ve .10'un altında değere sahip olan maddeler binişik olduğu için madde havuzundan çıkarılmıştır. Söz konusu sınır dâhilinde, 6 madde binişiklik özellikleri nedeniyle ölçek kapsamına dâhil edilmemiştir. Bunula birlikte, nomolojik geçerlilik göz önüne alınarak 2 madde havuzdan çıkarılmıştı. Bu bağlamda, iki faktörlü yapıya sahip, 12 maddeden oluşan ve toplam varyansın $\% 57,48^{\prime}$ ini açıklayan ölçek yapısı elde edilmiştir. AFA sürecinin tamamlanmasının ardından, ölçek yapısının sınanması için DFA uygulanmıştr. DFA sonuçları ile elde edilen uyum indekslerinin mükemmel düzeyde olduğu sonucuna ulaşılmıştır. Buradan hareketle, AFA ile belirlenen iki faktörlü ölçek yapısının DFA ile sınanarak doğrulandığı ve modelin tutarlıık gösterdiği sonucuna ulaşılmıştır.

AFA ve DFA süreçlerinin tamamlanması ile madde analizi uygulamaları yapılmıştı. Bu aşamada, Spearman-Brown metodu kapsamında \%27'lik alt ve üst gruplar oluşturulmuştur. Analiz sonuçları doğrultusunda elde edile $r$ değerleri, .30 sınırı kapsamında incelenmiştir. Elde edilen korelasyon katsayılarının her bir madde için yeterli olduğu sonucuna ulaşılmış ve bu noktada herhangi bir madde, ölçek kapsamından çıkarılmamıştı. Madde analizinin tamamlanması ile iç güvenilirlik analizleri yapılmıştır. Analiz sonuçlarına göre, ölçeğe ilişin Cronbach's Alpha katsayısı ,89 olarak bulunmuş ve bu değer ölçeğin oldukça güvenilir olduğu sonucuna ulaşılmasını sağlamıştır. Bununla birlikte, her iki faktörün Cronbach's Alpha katsayısı hesaplanmıştr. Değer adlı faktör için ,85 olarak bulunan katsayının, beklenti faktörü için .82 şeklinde olduğu görülmüştür. Buradan hareketle, faktörlerin oldukça güvenilir olduğu sonucuna ulaşılmıştır. Ayrıca, faktörlerin kendi aralarında ve ölçeğin tamamı ile yüksek korelasyona sahip oldukları ortaya çıkmıştır. Analiz sonuçları doğrultusunda, iki faktörlü ve 12 maddeden oluşan nihai ölçek elde edilmiştir.

Wozney, Venkatesh, ve Abrami (2006) tarafindan geliştirilen "Teknoloji Uyarlamaları Uygulama Ölçeği Bölüm 1", orijinal versiyonu 33 madde kapsamında değer, beklenti ve maliyet olmak üzere üç faktörden oluşmaktadır. Uyarlama sürecinin ardından elde edilen nihai ölçeğin değer ve beklenti adlı faktörler olmak üzere iki faktörden oluştuğu ve maliyet faktörüne ilişkin tüm maddelerin analiz sonuçları doğrultusunda ölçek bünyesi dışında kaldığı görülmüştür. Bu durumun nedeninin kültürler arası farklııklar ve Türkçe'nin dil yapısı ile ilgili olduğu düşünülmektedir. Nitekim uyarlama süreçlerinde karşılaşılabilecek bu tür durumlar üç genel kategoride toplanmaktadır: (1) kültürel farklılıklar ve dil farklılıkları, (2) teknik konular, dizaynlar ve metotlar, (3) sonuçların yorumlanması (Hambleton, Merenda, and Spielberger, 2004). Nitekim, ölçek faktörlerinin değişkenlik göstermesi literatürde çok sık karşılaşılan bir durumdur. Örneğin, Koehler ve Mishra (2005) tarafindan sunulan Teknolojik Pedagojik Alan Bilgisi (TPAB) çerçevesi yedi boyutta açıklanmaktadır. Fakat Graham, Burgoyne, Cantrell, Smith, Clair, ve Harris (2009)'in TPAB üzerine sundukları ölçek 4 boyuttan oluşurken Lee ve Tsai (2005) tarafindan sunulan TPAB çerçevesi 5 boyutta tanımlanmıştr. Bu bağlamda, faktörlerin değişkenlik göstermesi ve bazı faktörlerin tamamen modelin dışında kalması literatürde var olan ve kabul edilen bir durumdur.

Öğretmenlerin sınıflarında teknolojiyi kullanmaları halinde öğrencilerin öğrenme süreçlerine sunacakları destek (Cradler, McNabb, Freeman, \& Burchett, 2002; Roschelle, Abrahamson, \& Penuel, 2004; Bajcsy, 2002; Watson, 2007) ve inanç sistemlerinin öğretmen eylemleri üzerindeki etkisi dikkate alındığında (Russell, 0’Dwyer, Bebell, \& Miranda, 2004; Honey \& Moeller, 1990; Cuban, 2002; Fullan, 2001; Fullan, 2003; Guskey, 2002; Ringstaff \& Kelley, 2002; Sandholtz, Ringstaff,, \& Dwyer, 1997), öğretmenlerin teknoloji kullanımına yönelik inançlarının önemi ortaya çıkmaktadır. Örneğin, Coppola (2004) tarafindan yürütülen çalışmada, öğretmenlerin sadece değerine gerçekten inandıkları zaman teknolojiyi kullanacakları belirtilmiştir. Bu bağlamda, öğretim teknolojilerine yönelik öğretmen inanç düzeylerinin belirlenmesinin oldukça önemli olduğu ifade edilebilir. Uyarlama çalışması tamamlanarak geçerli ve güvenilir bir ölçek olduğu doğrulanan Teknoloji Uyarlamaları Uygulama Ölçeği Bölüm 1'in bundan sonraki araşttrmalarda söz konusu amaç için kullanılabileceği düşünülmektedir.

\section{Kaynakça}

Al-Awidi, H. M., \& Alghazo, I. M. (2012). The effect of student teaching experience on pre-service elementary teachers' self-efficacy beliefs for technology integration in the UAE. Educational Technology Research and Development, 60(5), 923-941.

Albion, P. R. (1999). Self-efficacy beliefs as an indicator of teachers' preparedness for teaching with technology. Proceedings from SITE 1999: Society for Information Technology \& Teacher Education International Conference. Chesapeake, VA: Association for the Advancement of Computing in Education (AACE). 
An, Y., \& Reigeluth, C. (2012). Creating technology-enhanced, learner-centered classrooms: K-12 teachers' beliefs, perceptions, barriers, and support needs. Journal of Digital Learning in Teacher Education, 28(2), 60-62.

Ashrafzadeh, A., \& Sayadian, S. (2015). University instructors' concerns and perceptions of technology integration. Computers in Human Behavior, 49, 62-73.

Bajcsy, R. (2002, September 9). Visions 2020: Transforming education and training through advanced technologies. Retrieved from http:// www.technology.gov/reports/TechPolicy/2020Visions.pdf

Berrett, B., Murphy, J., \& Sullivan, J. (2012). Administrator insights and reflections: Technology integration in schools. The Qualitative Report, 17(1), 200.

Bingimlas, K. A. (2009). Barriers to the successful integration of ICT in teaching and learning environments: A review of the literature. Eurasia Journal of Mathematics, Science \& Technology Education, 5(3).

Becker, H. J. (1994). How exemplary computer-using teachers differ from other teachers: Implications for realizing the potential of computers in schools. Journal of Research on Computing in Education, 26(3), 291-321.

Bigatel, P. M. (2004). Exploring the beliefs and attitudes of exemplary technology-using teachers (Doctoral dissertation). Retrieved from PennState.

Brislin, R. W. (1970). Back-translation for cross-cultural research. Journal of Cross-Cultural Psychology, 1(3), 185-216.

Campbell, D., Brislin, R., Stewart, V., \& Werner, O. (1970). Back-translation and other translation techniques in cross-cultural research. International Journal of Psychology, 30, 681-692.

Coppola, E. M. (2004). Powering up: Learning to teach well with technology. New York: Teachers College Press.

Cradler, J., McNabb, M., Freeman, M., \& Burchett, R. (2002). How does technology influence student learning?. Learning and Leading with Technology, 29(8), 46-49.

Cuban, L. (2001). Oversold and underused computers in the classrooms. Cambridge, Mtl: Harvard University Press.

Dolenc, K., \& Aberšek, B. (2015). TECH8 intelligent and adaptive e-learning system: Integration into technology and science classrooms in lower secondary schools. Computers \& Education, 82, 354-365.

Ertmer, P. A. (2005). Teacher pedagogical beliefs: The final frontier in our quest for technology integration?. Educational Technology Research and Development, 53(4), 25-39.

Ertmer, P. A., \& Ottenbreit-Leftwich, A. T. (2010). Teacher technology change: How knowledge, confidence, beliefs, and culture intersect. Journal of Research on Technology in Education, 42(3), 255-284.

Ertmer, P. A., Ottenbreit-Leftwich, A. T., Sadik, O., Sendurur, E., \& Sendurur, P. (2012). Teacher beliefs and technology integration practices: A critical relationship. Computers \& Education, 59(2), 423-435.

Ertmer, P. A., Paul, A., Molly, L., Eva, R., \& Denise, W. (1999). Examining teachers' beliefs about the role of technology in the elementary classroom. Journal of Research on Computing in Education, 32(1), 54-72.

Field, A. (2013). Discovering statistics using IBM SPSS statistics. London: Sage Publications.

Fishbein, M., \& Ajzen, I. (1975). Belief, attitude, intention and behavior: An introduction to theory and research. Reading, Mass.: Addison-Wesley.

Fullan, M. (2001). The new meaning of educational change (3rd ed.). London: Routledge Falmer.

Fullan, M. (2003). Changeforces with a vengeance. London: Routledge Falmer.

Graham, R. C., Burgoyne, N., Cantrell, P., Smith, L., St Clair, L., \& Harris, R. (2009). Measuring the TPACK confidence of inservice science teachers. TechTrends, 53(5), 70-79.

Guskey, T. R. (2002). Professional development and teacher change. Teachers and Teaching, 8(3), 381-391.

Hair, J. F., Black, W. C., Babin, B. J., Anderson, R. E., \& Tatham, R. L. (1998). Multivariate data analysis. Upper Saddle River, NJ: Prentice Hall.

Hambleton, R. K., Merenda, P. F., \& Spielberger, C. D. (Eds.). (2004). Adapting educational and psychological tests for cross-cultural assessment. London: Psychology Press.

Hermans, R., Tondeur, J., van Braak, J., \& Valcke, M. (2008). The impact of primary school teachers' educational beliefs on the classroom use of computers. Computers \& Education, 51(4), 1499-1509.

Hew, K. F., \& Brush, T. (2007). Integrating technology into K-12 teaching and learning: Current knowledge gaps and recommendations for future research. Educational Technology Research and Development, 55(3), 223-252.

Holland, D. L., Lachicotte, J. W., Skinner, D., \& Cain, C.(1998). Identity and agency in cultural worlds. London: Harvard University Press.

Honey, M., \& Moeller, B. (1990, August). Teachers' Beliefs and Technology Integration: Different Values, Different Understandings. Technical Report No. 6. Retrieved from https://files.eric.ed.gov/fulltext/ED326203.pdf

HSu, P. S. (2013). Examining changes of pre-service teachers' beliefs about technology integration during student teaching. Journal of Technology and Teacher Education, 21(1), 27-48.

Inan, F. A., \& Lowther, D. L. (2010). Factors affecting technology integration in K-12 classrooms: A path model. Educational Technology Research and Development, 58(2), 137-154. 
Jonassen, D.H. (1992). Designing hypertext for learning. In E. Scanlon \& T. O’Shea (Eds.), New directions in educational technology (pp. 123-131). New York: Springer-Verlag.

Jöreskog, K.G., \& Sörbom, D. (1993). Lisrel 8: Structural equation modeling with simpliscomm and language. Lincolnwood: Scientific Software International.

Kennedy, M. M. (1997, March). Defining an ideal teacher education program. Retrieved from https://msu.edu/user/mkennedy/publications/docs/Teacher\%20Ed/Kennedy\%20to\%20NCATE.pdf

Kim, C., Kim, M. K., Lee, C., Spector, J. M., \& DeMeester, K. (2013). Teacher beliefs and technology integration. Teaching and Teacher Education, 29, 76-85.

Koehler, M. J., \& Mishra, P. (2005). What happens when teachers design educational technology? The development of technological pedagogical content knowledge. Journal of Educational Computing Research, 32(2), 131-152.

Lee, M. H., \& Tsai, C. C. (2010). Exploring teachers' perceived self efficacy and technological pedagogical content knowledge with respect to educational use of the World Wide Web. Instructional Science, 38(1), 1-21.

Liu, S. H. (2012). A multivariate model of factors influencing technology use by preservice teachers during practice teaching. Journal of Educational Technology \& Society, 15(4), 137.

Locatis, C., Letourneau, G., \& Banvard, R. (1989). Hypermedia and instruction. Educational Technology Research \& Development, 38(2), 41-49.

Marsh, E.J., \& Kumar, D.D. (1992). Hypermedia: A conceptual framework for science education and review of recent findings. Journal of Educational Multimedia and Hypermedia, 1(1), 25-37.

McMahon, G. (2009). Critical thinking and ICT integration in a Western Australian secondary school. Journal of Educational Technology \& Society, 12(4), 269.

Moersch, C. (2002). Measurers of success-six instruments to assess teachers' use of technology. Learning and Leading with Technology, 30(3), 10-13.

Nespor, J. (1987). The role of beliefs in the practice of teaching. Journal of Curriculum Studies, 19(4), 317-328.

Nunnally, J., \& Bernstein, I. (1994). Psychometric theory. New York: McGraw-Hill.

Olivier, T. A., \& Shapiro, F. (1993). Self-efficacy and computers. Journal of Computer-Based Instruction, 20(3), 81-85.

Pajares, M. F. (1992). Teachers' beliefs and educational research: Cleaning up a messy construct. Review of Educational Research, 62(3), 307-332.

Richardson, V. (2003). Pre-service teachers' beliefs. In J. Raths \& A. C. McAninch (Eds.), Teacher beliefs and classroom performance: The impact of teacher education (pp. 1-22). United States: Information Age Publishing

Ringstaff, C., \& Kelley, L. (2002). The learning return on our educational technology investment: A review of findings from research. Retrieved from https://files.eric.ed.gov/fulltext/ED462924.pdf

Roschelle, J., Abrahamson, L. A., \& Penuel, W. R. (2004, April). Integrating classroom network technology and learning theory to improve classroom science learning: A literature synthesis. Proceedings from the Annual Meeting of the American Educational Research Association. San Diego, CA.

Russell, M., Bebell, D., O’Dwyer, L., \& O’Connor, K. (2003). Examining teacher technology use: Implications for preservice and inservice teacher preparation. Journal of Teacher Education, 54(4), 297-310.

Russell, M., O'Dwyer, L., Bebell, D., \& Miranda, H. (2004, May). Technical report for the USEIT study. Retrieved from http://www.bc.edu/ research/intasc/researchprojects/USEIT/pdf/USEIT_r11.pdf.

Sandholtz, J. H., Ringstaff, C., \& Dwyer, D. C (1997). Teaching with technology: Creating student-centered classrooms. New York: Teachers College Press.

Sugar, W. (2002). Applying human-centered design to technology integration: Three alternative technology perspectives. Journal of Computing in Teacher Education, 19(1), 12-17.

Teo, T. (2011). Factors influencing teachers' intention to use technology: Model development and test. Computers \& Education, 57(4), 2432-2440

Thomas, J. (2003). Reforming elementary science teachers' preparation: What about extant teaching beliefs?. School, Science and Mathematics, 103, 319-330.

Thompson, B. (2004). Exploratory and confirmatory factor analysis: Understanding concepts and applications. Washington, DC: American Psychological Association.

Wang, F., Kinzie, M. B., McGuire, P., \& Pan, E. (2010). Applying technology to inquiry-based learning in early childhood education. Early Childhood Education Journal, 37(5), 381-389.

Watson, J. F. (2007). A national primer on K-12 online learning. Retrieved from http://files.eric.ed.gov/fulltext/ED509633.pdf

Wozney, L., Venkatesh, V., \& Abrami, P. (2006). Implementing computer technologies: Teachers' perceptions and practices. Journal of Technology and Teacher Education, 14(1), 173-207.

Wright, V. H., \& Wilson, E. K. (2011). Teachers' use of technology: Lessons learned from the teacher education program to the classroom. 
SRATE Journal, 20(2), 48-60.

Yavuz, S. (2005). Developing a technology attitude scale for pre-service chemistry teachers. The Turkish Online Journal of Educational Technology, 4(1), 17-25.

Yoder, S. (1994). Math, microwoflds, and hypermedia. The Computing Teacher, 21(8), 18-20.

\section{EK 1. Ölçek Maddeleri}

D Sınıflarda bilgisayar teknolojisi kullanımı, öğrencilerin önemli geleneksel öğrenme kaynakların

(ör: kitaplar) ihmal etmesine neden olur. Sınıflarda bilgisayar teknolojisi kullanımı etkilidir, çünkü teknolojiyi başarılı bir şekilde uygulayabileceğime inanırım.

(1) (2) (3) (4) (5) (6)

D Sınıflarda bilgisayar teknolojisi kullanımı, öğrenci işbirliğini teşvik eder.

(1) (2) (3) (4) (5) (6)

Sınıflarda bilgisayar teknolojisi kullanımı, iletişim becerilerinin (ör: yazma ve sunum becerileri) gelişimini destekler.

(1) (2) (3) (4) (5) (6)

Sınıflarda bilgisayar teknolojisi kullanımı, eğitim bilimciler olarak öğretmenlerin kendilerini daha yetenekli/yetkin hissetmelerini sağlar.

(1) (2) (3) (4) (5) (6)

B Sınıflarda bilgisayar teknolojisi kullanımı, ancak öğrenme için teknoloji kullanımı konusunda ye-

terli öğretmen eğitimi olursa başarılı olur.

(1) (2) (3) (4) (5) (6)

Sınıflarda bilgisayar teknolojisi kullanımı, ancak teknik ekip düzenli olarak bilgisayarların bakımı-

nı yaparsa başarılı olur.

(1) (2) (3) (4) (5) (6)

D Sınıflarda bilgisayar teknolojisi kullanımı, öğrencilerin tüm yetenekleri için etkili bir araçtır.

(1) (2) (3) (4) (5) (6)

B

Sınıflarda bilgisayar teknolojisi kullanımı, eğer öğretmenler entegre edilecek bilgisayar teknolojilerinin seçimine katılırlarsa etkili olur.

(1) (2) (3) (4) (5) (6)

Sınıflarda bilgisayar teknolojisi kullanımı, öğrencilerin çevreleriyle uyum becerilerinin (ör: başkalarıyla ilişki kurma ya da çalışma becerileri) gelişimini destekler.

(1) (2) (3) (4) (5) (6)

Sınıflarda bilgisayar teknolojisi kullanımı, sadece kapsamlı/yaygın bilgisayar kaynakları erişilebilir olduğunda etkili olur.

(1) (2) (3) (4) (5) (6)

Sınıflarda bilgisayar teknolojisi kullanımı, önemli kavram ve düşüncelere yönelik öğrenci öğrenmelerini geliştirir.

(1) (2) (3) (4) (5) (6)

${ }^{*} D=$ değer; $B=$ beklenti 